Dicenda. Cuadernos de Filología Hispánica

ISSN: 0212-2952

http://dx.doi.org/10.5209/DICE.57714

\title{
¡O vos, dubitantes, creed las istorias e los infortunios de los humanales! Ficción alegórica y modos de "recontar" en los decires narrativos de don Íñigo López de Mendoza ${ }^{1}$
}

\section{Santiago Vicente Llavata ${ }^{2}$}

Resumen. Los decires narrativos de don Íñigo López de Mendoza representan una de las muestras más sobresalientes de la aclimatación de la ficción alegórica en la literatura medieval hispánica. Uno de los procedimientos centrales en el proceso de composición de estas obras se basa en la selección de recursos estilísticos orientados a recrear una atmósfera de irrealidad. Partiendo, pues, de esta premisa, el objetivo de este estudio se centra en detectar tales elecciones estilísticas e interpretarlas con las herramientas y conocimientos que nos brinda la Filología. De entre el conjunto de recursos expresivos de que dispone la lengua castellana medieval, nos centraremos de modo especial en tres fenómenos estilísticos de gran relevancia: los latinismos léxicos, las voces prestadas y las locuciones formadas con voces diacríticas.

Palabras Clave: Humanismo; Ficción alegórica; Íñigo López de Mendoza; Historia de la lengua; Fraseología histórica; Lexicología histórica.

[en] ; O vos, dubitantes, creed las istorias e los infortunios de los humanales! Allegorical fiction and ways of "recontar" in İnigo López de Mendoza's "decires narrativos"

Abstract. Íñigo López de Mendoza's "decires narrativos" are considered to be the best literary works related to the adaptation of allegorical fiction in Hispanic medieval literature. One of the main procedures in the process of composing these plays is based on the selection of the stylistic ways used to recreate fiction. Taking this hypothesis as a starting point, the aim of this study is to focus on the detection and the interpretation of theses stylistic options with the help of the tools and knowledge brought to us by the Philology. Of the many forms of expression which could be associated with $15^{\text {th }}$ century Spanish language, this study particularly highlights three stylistic ways: the influence of Latin lexis, loanwords and phrases with diacritic words.

Keywords. Humanism; Allegorical fiction; Íñigo López de Mendoza; History of Language; Historical Phraseology; Historical Lexicology.

Esta contribución se inscribe en el Proyecto de Investigación Fraseología de la lengua castellana en su diacronía: desde los orígenes hasta el siglo XVIII (FRASLEDIA), financiado por el Ministerio de Economía y Competitividad (Subdirección General de Proyectos de I+D), en el marco del Programa Estatal de Fomento de la Investigación Científica y Técnica de Excelencia (Subprograma de Generación del Conocimiento) con referencia FFI2013-44682-P. El proyecto, de carácter internacional y con una duración de cuatro años, se desarrolla en el seno del Departamento de Filología Española de la Universitat de València, y está dirigido y coordinado por la Dra. Da. Mª Teresa Echenique Elizondo y por la Dra. Da. M José Martínez Alcalde.

2 Universitat de València

Santiago.Vicente@uv.es 
Sumario. 1. Introducción. 2. Descripción literaria de los decires narrativos de don Íñigo López de Mendoza. 3. Modos de recrear la ficción alegórica: latinismos léxicos, voces prestadas y locuciones formadas con palabras diacríticas. 3.1. El latinismo léxico: nuevas voces para nuevas ficciones literarias. 3.2. Las voces prestadas como un modo de evocar mundos lejanos y exóticos. 3.3. Un recurso inédito en las formas históricas de la expresión literaria: locuciones formadas con palabras diacríticas. 3.3.1. Preliminares. 3.3.2. La locución a quarteles. 3.3.3. La locución a desora. 4. Consideraciones finales. 5. Obras citadas.

Cómo citar: Vicente Llavata, S. (2017). ;O vos, dubitantes, creed las istorias e los infortunios de los humanales! Ficción alegórica y modos de "recontar" en los decires narrativos de don Íñigo López de Mendoza, Dicenda. Cuadernos de filología hispánica, 35, 325-347.

\section{Introducción}

Los estudios más recientes de literatura medieval en el ámbito de la península ibérica se centran en determinar y establecer conexiones diversas entre las nacientes literaturas hispánicas en el contexto de la Edad Media ${ }^{3}$. Desde esta perspectiva renovada de estudio, la obra literaria de don Íñigo López de Mendoza se conforma como un espacio privilegiado para el análisis detenido de tales conexiones literarias y culturales.

El objetivo fundamental de este estudio se basa en identificar y analizar las elecciones estilísticas que utiliza Íñigo López de Mendoza en sus decires narrativos con el objetivo de recrear la ficción. Con el fin de dar marco a este cometido investigador, hemos elegido los dos primeros versos con que se inicia la Comedieta de Ponça, pues en ellos se encierra una significativa declaración de intenciones en torno a las fronteras difusas entre lo real y lo ficticio. Por otra parte, la referencia explícita a los modos o medios de representar esa ficción alegórica se expresa mediante el verbo recontar, que se integra en un campo semántico - el de la dimensión enunciativa del lenguaje - formado por una serie muy amplia de formas sinónimas, como son narrar, presentar, comunicar, testificar, compendiar, tractar, remitir, verificar, describir, relatar, afirmar, mencionar, contar, escribir, memorar, comentar... ${ }^{4}$

De entre el conjunto de recursos estilísticos de que dispone el marqués de Santillana en la lengua literaria cuatrocentista para recrear la ficción, nos centraremos en tres procedimientos estilísticos de gran relevancia: el uso de latinismos léxicos, la presencia de voces prestadas y el uso de locuciones formadas con palabras diacríticas $^{5}$. Nuestro plan de estudio parte de la hipótesis de que la presencia de este tipo de voces y locuciones -inéditas en la norma lingüística del siglo XV-podría estar motivada para recrear esa atmósfera de irrealidad y ficción en el contexto significativo del decir narrativo. El descubrimiento de esas elecciones estilísticas, junto con el análisis simultáneo de las fuentes literarias en juego (Lapesa, 1954 y 1957),

3 Un buen ejemplo de ello es la creación de asociaciones científicas como la Asociación Hispánica de Literatura Medieval (AHLM) o la Sociedad de Estudios Medievales y Renacentistas (SEMYR), que presentan como objetivo general promover la investigación de las diferentes literaturas medievales en el ámbito iberorrománico.

4 Extraídos de los prólogos con que se inician algunas de sus obras, como los Proverbios o Centiloquio, Bías contra Fortuna o el Prohemio e carta.

5 Para un estudio panorámico sobre la fraseología histórica, remitimos al apartado 3.3 de este artículo, donde se describirá someramente un estado de la cuestión. 
constituiría, a nuestro modo de ver, una senda metodológica muy provechosa, con vistas a reconstruir las fases varias por las que se ha forjado el estilo literario de Íñigo López de Mendoza ${ }^{6}$.

\section{Descripción literaria de los decires narrativos de don Íñigo López de Mendoza}

Los decires narrativos se inscriben en la primera etapa de la trayectoria literaria de don Íñigo López de Mendoza, anteriores todos ellos a 1437, excepto la Canonización de San Vicente Ferrer (Lapesa, 1957: 96). Es en este período en el que se puede apreciar la puesta en práctica de los conocimientos atesorados en su etapa formativa. En los decires narrativos, se aprecia, desde una visión de conjunto, un decidido acercamiento a la voluntad de recrear, mediante el discurso poético, la Antigüedad clásica (Rico, 1980: 295-351 y 2002: 44-58). Estos primeros acercamientos al mundo grecolatino, desde la actitud segura y ufana del que domina una técnica compositiva, se limitan al atesoramiento y superposición acumulativa de latinismos léxicos, semánticos, sintácticos y, en mayor grado, de latinismos gráficos (Gómez Moreno, 1994: 81-121; Pérez Priego, 2004: 63-99) ${ }^{7}$. Y el resultado en la expresión literaria se materializará en una presencia abrumadora y creciente de elementos sabios, que adornan y embellecen la materia poética, y que representan, al mismo tiempo, una primera aproximación a la Antigüedad clásica, no solo en forma de léxico, sino también en forma de referencias y reminiscencias literarias, tanto de la Antigüedad clásica como de los grandes autores medievales ${ }^{8}$ :
Algunos actores en sus connotados pidieron favores, subsidio e valençia al fulgente Apolo, dador de sçiençia; a Cupido e Venus, los enamorados; al Jove tronante en otros tractados, en bélicos actos al feroce Mares, a las nueve Musas en muchos logares insignes poetas vi recomendados9.

Sin embargo, en la evolución compositiva de los decires narrativos, la ostentación expresiva a que aludíamos se diluirá progresivamente en las creaciones maduras,

6 Para el estudio de la transmisión de su obra literaria, véase la entrada "Marqués de Santillana" en Pérez Priego (2002: 843-851).

7 A este respecto, afirma Lapesa (1954: 68): "No es ya la costumbre de respaldarse en autoridades, sino el deseo de lucir lo recién aprendido. Disculpemos esta inocente vanidad”. Y unas líneas más adelante, escribe: “[...] no obstante, en 1436, ningún poeta castellano anterior ni contemporáneo podía competir con Íñigo López en vastedad de intereses: ninguno se había lanzado tan ávidamente como él sobre los clásicos latinos ni sobre la literatura italiana".

$8 \quad$ Así lo afirma Lapesa (1957: 160-161): “Los decires narrativos son poesía docta y revelan que entre 1428 y 1436 Santillana poseía ya un buen caudal de lecturas, fruto de una dedicación iniciada en su mocedad. [...] Abarcaba, aparte de la Biblia, la antigüedad clásica accesible en compendios y traducciones -algunas de ellas hechas "a ruego e instancia" de don Íñigo-; las grandes figuras italianas del siglo XIV, obras francesas y catalanas y, finalmente, la poesía cultivada en Castilla desde Macías y Pero González de Mendoza".

9 Estrofa perteneciente a la Defunsión de don Enrique de Villena (II, vv. 9-16). En la citación de fragmentos de los decires narrativos, seguimos la edición crítica de Pérez Priego (1983-1991). 
donde las ejemplaridades y enseñanzas morales de la Antigüedad clásica adquirirán predominio sobre el aspecto meramente ornamental de la expresión poética ${ }^{10}$. Precisamente, uno de los motivos temáticos más recurrentes en los decires narrativos es el tratamiento dramatizado de la libertad y el destino humanos, como anteriormente habían tratado Petrarca y Boccaccio (Lapesa, 1957: 122-124; Lida de Makiel, 1978). La preocupación por el libre albedrío y la libertad humana hubo de ser muy intensa y contradictoria en el ambiente caballeresco del siglo XV y revelaba cómo las ideas del Humanismo se abrían paso; se trataba de un signo de los nuevos tiempos (Rico, 2002: 126-152):
Pero, maguer que seamos governados por fortuna, quédanos tan sólo una razón en que proveamos, de la qual, si bien usamos, annula su poderío:
éste es libre alvedrío, por donde nos governamos ${ }^{11}$.

En el proceso de composición de los decires narrativos, se aprecia el intento de armonizar las dos cosmovisiones presentes en la sociedad del cuatrocientos: por una parte, el universo tardomedieval de la sociedad caballeresca y cristiana y, por otra parte, el ámbito clarividente de la Antigüedad clásica ${ }^{12}$ (Gómez Moreno, 1994: 227242 y Rico, 2002: 126-152). Esta oscilación entre estas dos cosmovisiones en juego se aprecia de manera visible en la mayor parte de los decires narrativos, pero especialmente en los de mayor complejidad temática, como el Infierno de los enamorados, la Defunsión de don Enrique de Villena o la Comedieta de Ponça. Si algo es representativo y recurrente en todas estas obras es la descripción ampulosa de largos desfiles de personajes, en actitud ceremoniosa y aparatosidad de gestos, portadores de los saberes de la Antigüedad clásica (Pérez Priego, 2004: 63-99).

Nos interesa destacar, como aspecto complementario a los motivos temáticos, el tratamiento que se da del paisaje en el conjunto de los decires narrativos, pues en buena parte los recursos lingüísticos orientados a potenciar la ficción se encuentran precisamente en descripciones de paisajes de diverso signo. De un lado, encontramos la dilatada tradición literaria de representar el espacio amoroso, propicio para las efusiones sentimentales, por medio del vergel paradisíaco (Beltrán, 1988: 99-161 y 2009: 21-71). De otro lado, encontramos en el Sueño, en el Infierno de los enamorados y en la Defunsión de don Enrique de Villena principalmente, un paisaje de signo contrario: es el paisaje dantesco de "selvas aterradoras, páramos solitarios y

10 Tal como señala Lapesa (1957: 175), el descubrimiento de Séneca fue decisivo en el proceso de asimilación de las enseñanzas morales de la antigüedad.

11 Secuencia perteneciente a El Sueño, estrofa XXXIII, vv. 257-264.

12 En este sentido, afirma Lapesa (1957: 152): "Por una parte, el escenario natural y el ambiente humano que encuadra la acción de estos decires responden por completo al gusto y pensar de la sociedad caballeresca en su último y brillante florecimiento. De otro lado, el medievo cristiano ya no es la única fuente que suministra paradigmas de los valores más preciados: la antigüedad greco-latina, conocida trabajosamente en traducciones y extractos, ofrece ejemplaridades morales y artísticas que atraen la ávida mirada del caballero con afanes de humanista". 
cielos tempestuosos" (Lapesa, 1957: 154-155 y Pérez Priego, 2004: 63-99), donde un cortejo de personajes llora y se lamenta en actitud de refinamiento ${ }^{13}$.

En cuanto a la determinación de las fuentes literarias de cada uno de los decires narrativos, en términos generales se ha de afirmar que, a pesar de la indudable adopción de modelos literarios prestigiados en la literatura europea medieval, Íñigo López de Mendoza supo saber apartarse del modelo cuando convenía, con la consiguiente aportación de originalidad en el proceso compositivo de la obra literaria (Lapesa, 1957: 95-151).

En el caso de los decires narrativos menores, Rafael Lapesa destacará la fuerte impronta que dejaron en ellos las cantigas de los poetas gallego-castellanos (Beltrán, 1997: IX-XXX). Con respecto a la Querella de amor, también clasificada como decir narrativo menor, apuntará a la tradición literaria provenzal y catalana, en virtud de la estructura compositiva del "poema colectivo" (Cabré, 1998: 25-38). En cuanto a las fuentes literarias de la Visión, destaca la influencia decisiva que hubo de tener en don Íñigo el recuerdo de un poema de Francisco Imperial, en el que cuatro figuras alegóricas disputan su primacía. Si en el Triunphete de amor señala la influencia capital de los Trionfi de Petrarca en el plan general de la obra, no deja de destacar la influencia de la poesía castellana inmediatamente anterior, representada principalmente por Francisco Imperial. Asimismo, en el Sueño, aparte de reducir la aportación de la tradición literaria francesa a "gustos, modas y ambiente" (Lapesa, 1954: 37), se reconocen rasgos de la Fiammetta y del Laberinto d'amore de Boccaccio, así como de la Farsalia de Lucano, que invita a abordar el asunto pendiente de la suficiencia lectora de don Íñigo con respecto al latín. En el Infierno de los enamorados, la influencia capital procede de la Divina Commedia de Dante. Finalmente, la Comedieta de Ponça debe su plan general al De principum casibus de Boccaccio y, de manera indirecta, al Livre des quatre dames, de Alain Chartier, compuesto en torno a 1415 con motivo de la batalla de Azincourt (Lapesa, 1954: 50). Otros recuerdos literarios que pueden encontrarse en esta obra panegírica son los evangelios y las tragedias de Séneca, traducidos bajo la promoción cultural de don Íñigo López de Mendoza.

\section{Modos de recrear la ficción alegórica: latinismos léxicos, voces prestadas y locuciones formadas con palabras diacríticas}

En esa estrategia por recrear la ficción alegórica, además de recurrir a figuras vistosas que desfilan por bosques y praderas de forma ceremoniosa, el autor tiene a su disposición multitud de recursos estilísticos que refuerzan la representación de esa ficción. Pero lo cierto es que no todos esos instrumentos de estilo participan del mismo proceso ni presentan la misma relevancia en el ámbito de las formas históricas de expresión literaria. En el contexto que nos ocupa, nos centraremos en tres fenómenos de diferente signo que contribuyen a recrear y potenciar la ficción en el marco argumental del decir narrativo: el uso de latinismos léxicos como modo de

13 Así lo expone Lapesa (1957: 176): "Por otra parte, la inspiración auténtica nunca le faltó: sus decires narrativos interesan como expresión de exquisitas formas de vida y como índice de nuevas valoraciones culturales; pero sobre todo como creación poética. Las situaciones tópicas aparecen rejuvenecidas gracias al poder de una imaginación nunca ociosa, que sabe deleitar con sus fantasmagorías y situar al lector en el ambiente emocional requerido". 
recrear el universo grecolatino; la presencia de préstamos de otras lenguas romances como procedimiento para evocar espacios lejanos y exóticos, y el uso estratégico de locuciones formadas con palabras diacríticas, cuya presencia ya supone un índice de irrealidad en virtud de su opacidad semántica. Todos ellos, pues, a pesar de su diferente naturaleza lingüística, cumplen una función textual común: la de conformarse como recursos potenciadores de la ficción alegórica ${ }^{14}$ en el conjunto de los decires narrativos.

\subsection{El latinismo léxico ${ }^{15}$ : nuevas voces para nuevas ficciones literarias}

Con la implantación del ideal humanístico en territorio peninsular, la ficción alegórica cobra una importancia extraordinaria, por cuanto en ella se concitan gran parte de los valores señeros del Humanismo: galería exuberante de personajes mitológicos, motivos temáticos centrados en la libertad y destino humanos, formas compositivas inéditas en la literatura castellana $y$, especialmente, abrumadora presencia de latinismos y cultismos léxicos ${ }^{16}$.

Precisamente, respecto de este último punto, hay que tener presente que, a diferencia de otros subgéneros poéticos como las serranillas o las canciones, cuya transmisión oral se acompañaba de música, en el caso de los decires narrativos, la palabra debe suplir la sonoridad y el ritmo que proporcionaba la música; de ahí que el uso de latinismos y cultismos léxicos se oriente a imitar las cualidades de esta última (Lapesa, 1957: 162).

Aparte de esta función de carácter eufónico ${ }^{17}$, en esta propuesta de estudio defendemos que el uso de estos latinismos presenta otra función no menos importante. Nuestra hipótesis de trabajo se basa en la idea de que esos latinismos y cultismos léxicos refuerzan el carácter ficticio de lo que se cuenta. Ahora bien, pensamos que no todos estos elementos tendrían esa función encomendada, pues los que ya estaban aclimatados desde el siglo XIII ${ }^{18}$ con los primeros textos literarios no presentarían esa capacidad evocadora de ficción. Pensamos, por tanto, en los latinismos y cultismos léxicos documentados por primera vez en la primera mitad del siglo XV y,

14 En este sentido, habría que tener presente el significado de la voz alegoría que recoge San Isidoro en sus Etimologías, definida como 'habla extraña, ininteligible' (Taylor, 2000: 39-51).

15 Entendemos por "latinismo léxico" aquellas voces que se conservan totalmente fieles al étimo latino y que presentan una documentación posterior a finales del siglo XI, resultado de la implantación de las reformas carolingias con la enseñanza del latín medieval en la península ibérica, tal como delimita García Valle (2004: 153-154).

16 Así lo constata Lapesa (19819: 270): “El latinismo alcanza todavía con más intensidad al vocabulario. Ávidos de mostrarse a la altura de las nuevas maneras italianas, refinadas y sabias, los escritores introducen sin medida enorme cantidad de palabras cultas. En sólo una estrofa de Santillana encontramos exhortar, disolver, geno ('género', 'raza', latín g e n u s), subsidio, colegir, describir, servar 'conservar', estilo; y en otra de Juan de Mena, obtuso, fuscado 'oscuro', rubicundo, ígneo, turbulento, repunar 'repugnar'. Muchos de los cultismos citados y de los abundantísimos que saltan a la vista en cuanto tomamos un fragmento literario de la época no resultan hoy extraños porque llegaron a arraigar, ya en el lenguaje elevado, ya también en el habla llana; pero el aluvión latinista del siglo XV rebasaba las posibilidades de absorción del idioma; muchos neologismos no consiguieron sedimentarse y fueron olvidados pronto, como sucedió con geno, ultriz 'vengadora', sciente 'sabio', fruir 'gozar', punir 'castigar', y otros semejantes".

17 Tal como expone Lapesa (1957: 163), los cultismos "no son simple muestra de erudición, sino instrumentos expresivos merecedores de aprovechamiento artístico".

18 Para una visión de conjunto sobre el cultismo en español desde el punto de vista histórico, véanse los estudios de J. J. de Bustos Tovar (1974) y de G. Clavería (1991). 
especialmente, en la obra literaria de don Íñigo López de Mendoza ${ }^{19}$. El hecho de que fuesen totalmente inéditos y, por consiguiente, desconocidos para el público de la época provocaría un distanciamiento entre su experiencia sociolingüística y la forma literaria del decir, sin descartar, en forma muy puntual, el consiguiente bloqueo interpretativo de la secuencia argumental.

En el Sueño, donde se deja ver la influencia directa de la Fiammetta de Boccaccio y de la Farsalia de Lucano (Lapesa, 1957: 118), el poeta sueña en un vergel paradisíaco, hasta que, de repente, ese espacio agradable deviene en un escenario desapacible:

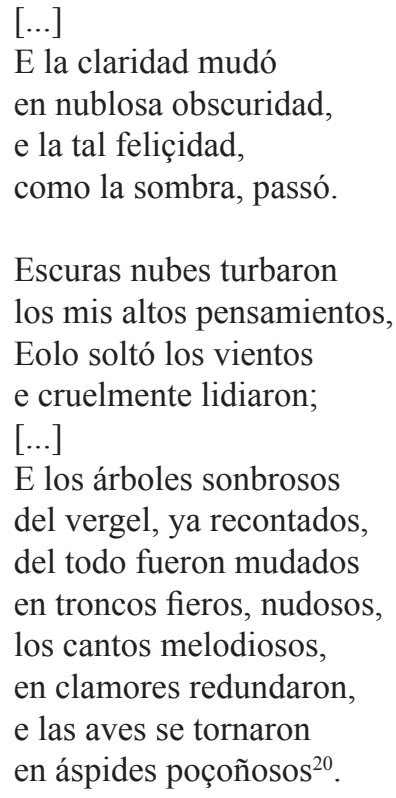

Nos interesa destacar el uso de la voz áspides en este contexto significativo del poema, en el que la finalidad es recrear una realidad ficticia como es el sueño del poeta. En la enumeración de esas circunstancias desapacibles, el poeta utiliza la voz áspides para contraponerla a aves. El hecho de que se documenten en la lengua castellana medieval otras voces para el concepto 'serpiente', como son vibra ${ }^{21}$, culebra $^{22}$, culebro $^{23}$,

19 Pensamos, por ejemplo, en los latinismos documentados por primera vez en la obra literaria de don Íñigo López de Mendoza que recoge I. López Bascuñana (1977: 288-292): admirable, adolescente, elegancia, inmenso, lector, lectura, magnifico, nocturno, notificar, oneroso, paciente, superlativo, visión, volumen, entre otros muchos. M. A. Pérez Priego (ed.) (1983-1991: 199-200), estrofa X, vv. 77-96.

21 De acuerdo con los datos del corpus Biblia Medieval, la voz se documenta en la Fazienda de Ultramar, datada en el primer tercio del siglo XIII: "e deportarse a el ninno sobrel forado dela uibra; en el forado del escorpion el [1]actant metra sue mano".

22 De acuerdo con los datos del Corpus diacrónico del español, la voz culebra se documenta en el Calila e Dimna, compuesto en 1251: "Et al roído de cómmo lo llevavan salió de su forado la culebra, et vido al religioso así, e conosçiólo [...]". Aparte de esta forma, existe otra variante gráfica - culuebra-, que se documenta por primera vez, según CORDE, en el Lapidario, fechado hacia 1250: "Et esta uertud muestra ella mas, descendiendo sobresta piedra la uertud de figura de culuebra que este sobrella un alacran; $\&$ ante si un aguamanil".

23 De acuerdo con los datos del Corpus diacrónico del español, la voz culebro se documenta en el Libro de Alexandre, compuesto hacia 1240: "En tierras de Egipto, -en letras fue trobado-, / fabló un corderuelo que era 


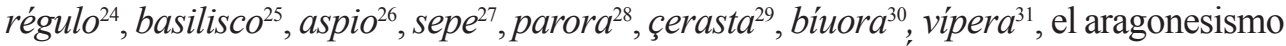 escurçón $^{32}$ o los genéricos serpiente ${ }^{33}$ y sierpe $^{34}$, indica que Íñigo López de Mendoza}

rezient nado, / parió una gallina un culebro irado ; / era por Alexandre tod'esto demostrado". Al igual que en el par léxico culebra / culuebra, existe también otra variante gráfica -culuebro-, que se documenta por primera vez, según CORDE, en el Lapidario, fechado hacia 1250: "E pues quant mordia el culuebro al baron, cataba al culuebro d' arambre e sanava. Movieronse fijos de Israel e [posaron en Obot]. *Movieronse de Obot * e pasaron en las islas de los vados, * en el yermo, a vista de Moab e a parte de Orient".

24 El Fichero General de la Real Academia Española presenta 147 papeletas de documentación en las que se pueden comprobar las diferentes acepciones de esta voz a lo largo del tiempo: 'serpiente' (equivalente al basilisco), 'aligación de dos metales (estaño y antimonio)' y 'gobernador de un territorio'. En cuanto a su documentación en las versiones bíblicas romanceadas, su presencia se da desde la Biblia prealfonsí, fechada hacia mediados del siglo XIII: "El venino deillos / assi como venino de sierpe / assi como de regulo sordo que cierra sus / oreillas". Por su parte, Alonso de Palencia la incluye en su Universal vocabulario en latín y romance a la hora de definir la voz latina SIBǏLUS: 'serpiente llamado regulo que chifla ante que muerda o ante que arremeta. En griego se dize basilisco'.

25 El Vocabulario de romance en latín de Antonio de Nebrija codifica la voz basilisco y la define como 'serpiente en África' y la hace equivaler al latín regūlus -i. Por su parte, el Diccionario de Autoridades la define en estos términos: 'Especie de serpiente, que según Plinio y otros autores se cría en los desiertos de África. Tiene la cabeza sumamente aguda, y sobre ella una mancha blanca a modo de corona de tres puntas, los ojos son mui encendidos y roxos. El cuerpo es pequeño, y el color de él tira a negro, salpicado de manchas blancas, la cola es larga, y delgada, y de ordinario la trahe enroscada. Con el silvo ahuyenta las demás serpientes, como Rey que presume ser de todas, por lo que es llamado también Régulo. Es fama vulgar que con la vista y el resuello mata, por ser eficacísimo su veneno. Es voz puramente griego, de quien la tomó el latín Basiliscus. Regulus'. En el corpus Biblia Medieval, la voz basilisco se documenta en la General Estoria: "E echara venino como basilisco, para quien dize en la letra de la Biblia regulus, que quiere dezir tanto como rey pequeñuelo, porque el basilisco rey es de las animalias que andan rastrando". El mismo marqués de Santillana utiliza el adjetivo basileo en la estrofa XLV (vv. 353-360) de El Sueño: "e fuémosnos açercando / donde la deessa estava / do mi viso vaçilava / en su fulgor acatando. / Concluyo determinando / qu'el animal basileo / e la vista del linçeo / la miraran titubando".

26 De acuerdo con los datos del corpus Biblia Medieval, la voz se documenta en el versículo 11 del Libro de Isaías de la Biblia prealfonsí, representada mediante los códices E8/E6 y datada hacia mediados del siglo XIII: "E el ninno de la teta trebeiara a los forados del aspio e el ninno que mamare metra la mano en la cueua de la sierpe que es llamada regulus". Por el contrario, en las versiones bíblicas romanceadas pertenecientes al siglo XV, la variante que predomina es justamente aspido.

27 De acuerdo con los datos del Corpus diacrónico del español, la voz sepe se documenta en la quinta parte de la General Estoria de Alfonso X El Sabio, datada hacia 1280: "Et es la natura destas culebras presteres contraria a la de las serpientes sepes ca las sepes tuellen el cuerpo a que enpeçonnan menguandole fasta que le desfazen \& las presteres fazenle finchar \& que creçen fasta que matan otrosy”.

28 Ninguno de los córpora consultados ofrece documentación para esta voz.

29 De acuerdo con los datos del Corpus diacrónico del español, la voz çerasta se documenta en la quinta parte de la General Estoria de Alfonso X El Sabio, datada hacia 1280: "guardan las conchas en que nasçe el aljofar \& del cuero de la serpiente çerasta de libia biujendo avn la serpiente de que fuera".

30 De acuerdo con los datos del banco de datos Biblia Medieval, la voz se documenta en el versículo 30 del Libro de Isaías de la Biblia prealfonsí, representada mediante los códices E8/E6 y datada hacia mediados del siglo XIII: "Esta es carga delas bestias de parte de abrego. En tierra de tribulation e de quexa, la leona e el leon dellos, biuora e regulo uolador [...]".

31 De acuerdo con el Diccionario del castellano del siglo XV en la Corona de Aragón (DiCCA-XV), la voz vípera se documenta por primera vez en 1471: "e sea vntado con açeite e en·el qual açeite sea cocha vna | vipera | o mas e sera rrenobada la carne e todo el cuero e asi". En cambio, el Corpus diacrónico del español ofrece como primera documentación la Vida de Santo Domingo de Silos, escrita por Gonzalo de Berceo hacia 1236: "Cató al leedor esa vípera mala, / dixo: "Non me afinques, fraire, sí Dios te vala, / otros de ti mejores me afincan que salga / cerca de ti los tienes, a ti no te incala".

32 De acuerdo con el Diccionario del castellano del siglo XV en la Corona de Aragón (DiCCA-XV), la voz escurçón se documenta por primera vez en 1470: "dize Salamon. asy como non es aspereza sobre aquella del tosygo del | escurçon | todo asy non es maliçia sobre aquella de·la fenbra”.

33 De acuerdo con los datos del Corpus diacrónico del español, la voz serpiente se documenta por primera vez en la obra Semejanza del mundo (BNM Ms. 3369), de autor anónimo, y fechada en torno a 1223: "Es otra ysla en Espana que dizen veso en toda esta ysla que tiene gran espaçio non ha serpiente ninguna".

34 Por su parte, de acuerdo con los datos del Corpus diacrónico del español, la voz sierpe se documenta en la Vida 
busca reforzar el clima de irrealidad que supone un sueño mediante el uso de un latinismo ajeno al habla popular. Es cierto que pueden formularse multitud de condicionantes a la hora de seleccionar una voz en el contexto de la técnica poética, como es el condicionamiento de la métrica y de la rima ${ }^{35}$, la búsqueda de la sonoridad del verso, la activación de valores connotativos o, incluso, una razón de variación léxica; de hecho, en la estrofa inmediatamente siguiente se lee: "E la farpa sonorosa / que recuento que tañía, / en sepes se convertía / de la grand sirte arenosa / e con ravia viperosa / mordió mi siniestro lado assí desperté turbado / e con angustia raxosa ${ }^{36 "}$. El hecho de que Íñigo López de Mendoza utilice en este contexto la voz sepes podría deberse a la necesidad imperiosa de ser transparente desde el punto de vista de la recepción de la obra literaria ${ }^{37}$, pues se trata de una secuencia en la que los hechos narrados presentan una relevancia decisiva a la hora de interpretar el marco argumental del poema ${ }^{38}$. En lo que respecta a la selección léxica, se trata, pues, de una continua y trabajosa adaptación a las coordenadas temáticas y estructurales del poema ${ }^{39}$.

Asimismo, otro dato contextual significativo en el estudio de esta voz es el soneto veintiséis, estudiado por Deyermond (2007: 175-203):

Non de otra guisa el índico serpiente teme la encantación de los egipcios que vos temedes, señora excellente, qualquiera relación de mis servicios. Porque sabedes, presente o absente, mis pensamientos e mis exercicios son loarvos e amarvos solamente, pospuesta cura de todos officios. Oídme agora, después condenadme si non me fallardes más leal que los leales; e si tal, sacadme de tan grand pena a sentid mi mal. E si lo denegades, acabadme: peor es guerra que non lid campal ${ }^{40}$.

de Santo Domingo de Silos, datada hacia 1236: "Prendié forma de sierpe el traïdor provado, / poniésseli delante el pescueço alçado, / oras se facié chico, oras grand desguisado, / a las veces bien gruesso, a las veces delgado". Otra primera documentación próxima es la registrada en la Biblia prealfonsí, fechada, tal como se ha descrito, hacia mediados del siglo XIII: "\& por esto embio dios enel pueblo serpientes de fuego, et por las muertes, e por la quexa delas sierpes".

35 Para un estudio de conjunto sobre la incidencia de la métrica y de la rima en la conformación de un estándar oral en la lengua poética castellana medieval, véanse los libros de Pla Colomer (2012 y 2014).

36 Secuencia perteneciente a El Sueño, estrofa XIII, vv. 97-104.

37 No es esta una actitud ajena al marqués, tal como recuerda Lida de Malkiel (1984: 252): “Así también Santillana tiene la cautela de traducir los latinismos que usa (Soneto, Cancionero..., N. 196: ¿Fué visto bello o lide tan mortal...?)".

38 A diferencia de la estrofa anterior, cuya función en el marco argumental del poema reside en describir esas circunstancias a las que aludíamos anteriormente.

39 De hecho, en otra secuencia poética perteneciente a la Comedieta de Ponça, a la hora de describir la escuadra italiana utiliza la voz prestada bixa 'serpiente' (procedente del italiano biscia) para referirse al escudo de la familia Visconti de Milán. En esta ocasión, pues, el efecto estilístico que persigue el poeta castellano sería, quizás, contextualizar desde el punto de vista idiomático los bandos en guerra.

40 Pérez Priego (1983-1991, I: 286). 
Como puede observarse, en él se documenta la voz serpiente en el primer verso en posición de rima. De acuerdo con la imagen — presente ya en los salmos- del áspid que se tapa los oídos para no caer en el encantamiento, Deyermond apunta como fuentes probables tanto la obra De rebus familiaribus ("velut aspis, incantatoris voce non auditur", III.22) como la sextina seis de las Rimas de Francesco Petrarca ("Nulla al mondo è che non possano i versi: / e li aspidi incantar sanno in lor note...", vv. 28-29), en las que, como se aprecia, sí que aparecen las voces aspis y aspidi, frente a Santillana, que prefiere la voz serpiente. No así en El Sueño, que opta decididamente por el latinismo áspide.

De forma complementaria, si atendemos a las primeras documentaciones de las voces referidas al concepto 'serpiente' en la lengua castellana medieval, es fundamental dejar constancia de la variante romanceada aspido $^{41}$, cuyas primeras apariciones remiten tanto al scriptorium de Juan Fernández de Heredia ${ }^{42}$ — con la traducción al aragonés de las Vidas paralelas de Plutarco-, como a la Biblia de Mosé Arragel, fechada esta última en el primer tercio del siglo $\mathrm{XV}^{43}$. De hecho, el propio marqués utiliza en el prólogo a sus Proverbios (Pérez Priego, 1983-1991, II: 102) otra variante próxima a aquella bajo la forma aspio $^{44}$ :

Nin por temor de poçoñosos aspios, nombrados sepes parozas, çerastras, non todos los otros linages de poçoñosas sierpes, lo cual todo contrastava e resistia la su espada invicta ${ }^{45}$.

A pesar, pues, de conocer las variantes romanceadas aspido y aspio, Íñigo López de Mendoza opta en El Sueño por el latinismo áspide en virtud de su sonoridad y de su capacidad para evocar irrealidad y fantasía.

\subsection{Las voces prestadas como un modo de evocar mundos lejanos y exóticos}

Hasta ahora se ha podido comprobar la aportación de los latinismos a la hora de conferir irrealidad en el marco argumental del decir narrativo. Ahora es el momento de analizar con detalle la presencia de voces prestadas en el contexto poético.

${ }^{41}$ Haciendo gala de esa dualidad del latín del siglo XV a que se refería Lida de Malkiel (1984), con la convivencia de latinismos stricto sensu y "latinismos a medio romancear", como son esecrables, mistura, esperiençia, ynicos, omeçidaynorançias, perfeto, inteleto, entre otros muchos. En el caso de aspido, al provenir de la voz latina ASPIS ASPILIS, perteneciente al paradigma de la tercera declinación, su proceso de romanceamiento consistió en la adición del morfema gramatical -o, con la consiguiente reestructuración de su esquema silábico.

42 S. Dworkin (2005: 652), siguiendo el planteamiento de Harris-Northall (1999), destaca la decisiva importancia de Aragón y, en particular, del entramado cultural herediano a la hora de valorar la aparición y difusión de latinismos al castellano: "Varios latinismos se documentan por primera vez en textos del siglo XIV procedentes de Aragón, sobre todo del scriptorium de Juan Fernández de Heredia (m. 1396) antes de que salgan en textos castellanos del siglo XV, p. ej. débil, difícil, fácil, fértil, (im)posible, útil”.

43 De acuerdo con las informaciones bibliográficas aportadas por Schiff (1978 [1905]), hay que señalar que estas dos obras formaban parte de la selecta y amplia biblioteca del humanista castellano.

44 Gómez Moreno y Kerkhof (2003: 371) explican que Íñigo López de Mendoza se basa en la General Estoria V, cuya fuente es el libro IX de la Farsalia de Lucano.

45 Nótese que el adjetivo poçoñosos acompaña tanto a áspides en El Sueño como a aspios en los Proverbios. Ello nos permite reforzar nuestra interpretación a la hora de entender las elecciones léxicas que practica Santillana como plenamente conscientes y meditadas. 
El fenómeno de las voces prestadas en el marco de las varias tradiciones literarias en territorio hispánico ofrece un conjunto ilimitado de posibilidades de estudio, pues son muchas las aplicaciones metodológicas que pueden ser puestas en práctica. Uno de los ámbitos más fructíferos a la hora de examinar las mutuas relaciones léxicas entre los diversos espacios culturales europeos es el de la traducción ${ }^{46}$, por cuanto en ella se ha de partir necesariamente de un texto original que, de modo inevitable, condiciona las múltiples decisiones a las que se enfrenta el traductor.

En nuestro caso, partimos de un conjunto de composiciones poéticas de un determinado autor, con unas características bien definidas ${ }^{47}$. Uno de los rasgos definitorios del conjunto de los decires narrativos y, especialmente, de aquellos con un entramado argumental más complejo, consiste en la presencia de una corte majestuosa de personajes ilustres, que desfilan de forma ceremoniosa por bosques y prados, en actitud aleccionadora o ejemplarizante. En la descripción detallada y preciosista de estos escenarios ${ }^{48}$, emergen voces y locuciones que, por formar parte de un determinado ámbito o actividad, pueden representar procesos de transferencia léxica y fraseológica en virtud de su pertenencia a una cultura lingüística determinada. En este sentido, afirma Lapesa (1957: 167) en el epígrafe dedicado a la descripción del estilo de los decires narrativos:

Si el latinismo satisfacía las apetencias cultas, el gusto por lo exótico favorecía el uso de voces foráneas. Hay en el léxico del Marqués, como en toda la literatura castellana de su tiempo, un estrato ya viejo de procedencia francesa o provenzal, al que la vida de corte había añadido préstamos recientes (cota, cosser 'corcel', page, galante, balada, rondeles, etc.). [...] Es probable que en algún caso no se trate de influjo francés, sino catalán, recibido por el joven Íñigo López cuando servía de copero al que después fue rey Magnánimo.

En cada uno de los decires narrativos, se pueden encontrar, pues, tanto voces como locuciones que son resultado de procesos de transferencia léxica o fraseológica, respectivamente. La función textual de estos préstamos en el marco argumental del decir narrativo reside en su capacidad potencial de evocar mundos lejanos y exóticos, orientados a crear escenarios de irrealidad y fantasía. El uso estratégico de estos préstamos constituye, pues, otro de los modos de recrear la ficción.

En el decir narrativo En mirando una ribera, se documenta la voz roçegante. Como puede comprobarse, este adjetivo modifica al sustantivo ropa junto con los adjetivos estranjera, bordada y los sintagmas adjetivales fecha al modo de Bravante y passante del estribera:

En mirando una ribera, vi venir por un grand llano un hombre que cortesano parecía en su manera.

46 Véase el estudio de J. A. Pascual (1974) sobre la traducción de la Divina commedia por don Enrique de Villena.

47 Para una descripción completa de estos rasgos, véase Lapesa (1957: 95-177), así como el estudio introductorio de Pérez Priego (1983-1991: 29-37).

48 Valga como ejemplo la secuencia siguiente: "Ropas trahen a sus guisas, / todas fendidas por rayas, / do les paresçen sus sayas / forradas en peñas grisas; / de martas e ricas sisas / sus ropas bien asentadas, / de azeituní, / quartonadas, / de filo de oro brocado" (Cantar a sus fijas loando su fermosura). 


\begin{abstract}
Vestía ropa estranjera, fecha al modo de Bravante, bordada, bien roçegante, passante del estribera ${ }^{49}$.
\end{abstract}

De acuerdo con el estudio de Colón (2002: 373-402), su significado se corresponde con el de 'dicho de una vestidura: vistosa y muy larga' ${ }^{50}$. El adjetivo roçegante se aplica, pues, a vestidos largos y vistosos, lucidos por personajes de alta alcurnia. Por otra parte, la segunda acepción que codifica el diccionario académico - 'vistoso', 'ufano'- representa la evolución semántica de este primer significado y constituye una voz de uso en español actual, si bien circunscrita a los sociolectos cultos.

Tal como demuestra el profesor Colón en su estudio, el adjetivo roçegante constituye un préstamo del catalán medieval rossegant, que proviene, a su vez, del verbo catalán medieval rossegar ${ }^{51}$. En vista de las primeras documentaciones ofrecidas por Colón, parece ser que el primero en utilizar esta voz en el discurso literario en lengua castellana fue precisamente don Íñigo López de Mendoza ${ }^{52}$. En relación, pues, con la adopción de este préstamo, tal como ha recordado con oportunidad el profesor Pérez Priego (2003: 35-36), el ambiente cultural y literario del cuatrocientos en los diferentes territorios de la antigua Corona de Aragón fue decisivo en la formación literaria e intelectual de Íñigo López de Mendoza. Se nutrió intelectual y espiritualmente junto a don Enrique de Villena ${ }^{53}$, a quien consideró uno de sus maestros (Cátedra, 1996). Inició y consolidó lazos personales y profesionales junto a poetas tan representativos como mosén Jordi de Sant Jordi, Andreu Febrer o el poeta universal Ausiàs March, quienes sirvieron al rey Alfonso $\mathrm{V}$ el Magnánimo en sus numerosas campañas militares y diplomáticas en Italia ${ }^{54}$. Todos ellos participaron en un ambiente cultural y literario plenamente imbuido de las galas retóricas y de los nuevos aires de pensamiento procedentes de la Antigüedad clásica ${ }^{55}$.

Tal como se ha descrito con relación al uso del latinismo áspides en El Sueño, también el hecho de que la voz roçegante y su familia léxica resulten inéditas en la

49 Pérez Priego (1983-1991: 143), estrofa I, (vv. 1-8).

50 S.v. rozagante, en la edición electrónica del Diccionario de la lengua española de la RAE y ASALE.

51 En el catalán actual está mucho más extendida la variante arrossegar; de hecho, el Diccionari de la llengua catalana de l'Institut d'Estudis Catalans remite la variante rossegar a la entrada arrossegar.

52 También constituye primera documentación el participio roçegadas, registrado en el Planto de la reina doña Margarida de Prades, estrofa XII, vv. 78-84: "Allí fueron los troyanos / con vanderas roçegadas / e las fenbras muy loadas / de los puebloáspids siçilianos / allí fueron los de athenas / e las reynas de miçenas / e fueron los asyanos".

53 Para un estudio de los catalanismos en la obra de don Enrique de Villena, véase Eberenz (1995).

54 A este respecto, Lapesa (19819: 267), evoca este nuevo signo de los tiempos en estos bellos términos: "La antigüedad no es para los hombres del siglo XV simple materia de conocimiento, sino idea superior que admiran ciegamente y pretenden resucitar, mientras desdeñan la Edad Media en que viven todavía y que se les antoja bárbara en comparación con el mundo clásico. Alfonso V concierta una paz a cambio de un manuscrito de Tito Livio".

55 Gómez Moreno (2010: 10) incide también en ese cambio de paradigma que ya se atisbaba: "Más importa el hecho de que, al final del siglo XV, en España hubiesen triunfado los ideales lingüísticos del Humanismo, con la enseñanza universitaria del griego, la búsqueda de un latín próximo a los clásicos y la exaltación del castellano por su mayor parecido con la lengua del Lacio. También los géneros humanísticos (epístolas, discursos y diálogos, o la historiografía y la biografía) encontraron el terreno abonado en nuestra tierra. La rápida aclimatación de las ideas y los patrones de la Italia de los humanistas es el lógico resultado de dos fenómenos: en primer lugar, los vínculos preferentes que la unían con la Corona de Aragón; en segundo, las estancias cada vez más frecuentes y prolongadas de españoles (vale decir, castellanos, aragoneses y portugueses) en tierra italiana, que sumaban por lo común los motivos profesionales a la pasión erudita". 
norma culta del español cuatrocentista, revela hasta qué punto la elección de este tipo de voces supondría un significativo estímulo a la hora de evocar una atmósfera de ficción y exotismo, propicia al marco argumental del decir narrativo.

\subsection{Un recurso inédito en las formas históricas de la expresión literaria: locuciones formadas con palabras diacríticas}

\subsubsection{Preliminares}

De un tiempo a esta parte, el estudio de la fraseología ha cobrado un impulso extraordinario en la lingüística hispánica. Desde el estudio pionero de Julio Casares (1992 [1950]), se ha llegado a conformar una teoría fraseológica que, si bien todavía le queda por responder a interrogantes esenciales en su caracterización como disciplina (Penadés Martínez, 2012: 279-285), presenta las herramientas adecuadas para profundizar en su estudio ${ }^{56}$. Ese desarrollo de la fraseología teórica ha venido acompañado de la necesidad ineludible de estudiarla en su dimensión histórica. Así, partiendo de la idea de que la naturaleza gramatical de las unidades fraseológicas proviene de etapas históricas anteriores, se hace más que necesario atender al proceso global de institucionalización que acompaña a estas unidades a lo largo del tiempo ${ }^{57}$.

Existe un cierto consenso a la hora de determinar qué unidades forman parte de la fraseología ${ }^{58} \mathrm{y}$, especialmente, qué unidades ocupan su centro de estudio. En este sentido, teniendo en cuenta las propiedades básicas de pluriverbalidad, de fijeza y de idiomaticidad, las locuciones formadas con voces diacríticas ${ }^{59}$ conformarían ese centro descrito (García-Page, 1991), pues, si partimos de la consideración de que lo fraseológico se manifiesta con la suspensión de la regularidad entendida en su sentido gramatical, estas unidades formadas con palabras idiomáticas cumplen a la perfección con ese requisito esencial. En ese proceso de institucionalización al que

56 Aparte del estudio pionero de Julio Casares (1992 [1950]), habría que añadir las referencias sobre teoría fraseológica que han ido apareciendo en los últimos decenios, como son, por orden cronológico, los estudios de Zuluaga Ospina (1980), Corpas Pastor (1996), Martínez Marín (1996), Wotjak (1998), Ruiz Gurillo (1997 y 2001), Montoro del Arco (2006), García-Page (2008) y Penadés Martínez (2012).

57 Echenique (2008: 387), se refiere a esta relación de mutua dependencia en estos términos: “A esta consideración, general y unánime a la hora de abordar el análisis de las unidades fraseológicas, convendría añadir que, en realidad, nos enfrentamos a ellas de la misma manera que a un texto del pasado de la propia lengua, en que la sintaxis se ha vuelto rígida, con el consiguiente bloqueo de los principios de percepción y reformulación en su sentido gramatical (Echenique 2003), por lo que la perspectiva diacrónica se revela fundamental". Asimismo, Echenique (2008: 388), destaca la falta de atención que ha recibido el estudio de la fraseología desde el punto de vista histórico: "La perspectiva histórica, en cambio, apenas ha sido objeto de atención, si bien es verdad que los estudios de orientación pragmática han comenzado a centrar su interés sobre el problema del cambio lingüístico tratando de buscar las causas por las que sintagmas libres han pasado a convertirse en secuencias inmovilizadas (Martín Zorraquino 2001; Pons y Ruiz 2001). En un futuro no muy lejano este tipo de estudios deberá continuar creciendo hasta posibilitar la construcción de una historia global de las unidades fraseológicas (Echenique 2003), además de la historia particular de cada una de ellas, tareas apenas iniciadas".

58 Según se parta de una concepción ancha o estrecha del universo fraseológico. Para una visión de conjunto sobre qué unidades deben formar parte de la fraseología, véase Ruiz Gurillo (1997: 55-73) y García-Page (2008: 2022).

59 Define García-Page (2008: 352) el fenómeno de las voces diacríticas como el proceso por el cual una voz no presenta vitalidad de manera aislada en el uso lingüístico actual, sino que tan solo tiene existencia en la estructura de la locución en la que se integra. 
aludíamos unas líneas más arriba, la atención a este tipo concreto de locuciones se hace más que necesario, pues de su descripción y ordenación en paradigmas de formación dependen estrechamente los objetivos de gran alcance a los que aspira a dar respuesta esta disciplina.

En el marco, pues, de la fraseología histórica, existen diferentes líneas de investigación ${ }^{60}$ que, dada la novedad tanto de esta disciplina como de sus propuestas metodológicas, quedan todavía por explorar ${ }^{61}$. Una de esas aplicaciones metodológicas se basa, precisamente, en el estudio histórico-estilístico de la fraseología en el ámbito de la historia literaria ${ }^{62}$. El cometido fundamental de esta propuesta reside en concebir las unidades fraseológicas como elementos especialmente significativos a la hora de conformar el sentido interpretativo de la creación artística, al tiempo que pueden resultar indicadores activos a la hora de delimitar multitud de entornos discursivos literarios. De acuerdo con esta concepción, el uso consciente de ciertas unidades fraseológicas con unos rasgos bien definidos se conformarían como elementos estratégicos tanto a la hora de identificar un subgénero literario como a la hora de iluminar las claves interpretativas de una obra literaria determinada.

\subsubsection{La locución a quarteles}

La Comedieta de Ponça es un extenso poema alegórico en el que se narra el desgraciado caso de la casa real aragonesa, apresada por una escuadra genovesa dirigida por el duque de Milán (Gómez Moreno y Kerkhof, 2003: 44). Tras la preceptiva invocación a Júpiter y a las Musas ${ }^{63}$, comienza la descripción del tiempo en que se desarrolla el marco de la narración. En ese propósito por difundir historias verdaderas en el marco de la ficción alegórica, Íñigo López de Mendoza inicia la narración de la batalla con la evocación, con todo detalle, de los blasones de armas de las respectivas escuadras:

La segunda tarja de un balaxo ardiente era e de amarilla gema pomelada, cuyo nombre dixe non táçitamente; e cada qual poma con nudos ligada, de verde carbunclo al medio esmaltada. La terçera e quarta castillo e león eran a quarteles; e dexo el blasón, ca nuestra materia non es començada ${ }^{64}$.

60 Una de esas líneas a las que se hace referencia se centra en el estudio histórico de la presencia y forma de presentación de las unidades fraseológicas en las obras lexicográficas. A este respecto, consúltese el libro de Álvarez Vives (2013), referido al estudio contrastivo de las locuciones en los diccionarios de Vicente Salvá (1846) y de Esteban Pichardo (1836).

61 Para la delimitación de los objetivos y principios de la fraseología histórica, véanse los estudios de Echenique Elizondo (2003, 2008a y 2008b), así como el capítulo sexto del libro de Echenique Elizondo y Martínez Alcalde (2013).

62 Para el estudio de la fraseología en el contexto de una obra literaria, véase el libro de Vicente Llavata (2011) acerca del análisis de las locuciones en la obra literaria de don Íñigo López de Mendoza.

63 Para un estudio sobre la invocación de Júpiter y las Musas, véase Curtius (1955: 324-348).

64 Pérez Priego (ed.) (1983-1991: 59), estrofa VIII, vv. 57-64. 
En esa exuberante descripción de elementos, Íñigo López de Mendoza utiliza una unidad fraseológica para evocar la forma del escudo de armas del reino castellano-leonés; se trata de la locución a quarteles ${ }^{65}$. La unidad cuartel es voz disponible en el español actual, si bien se trata de una voz técnica perteneciente a diversos ámbitos, como el de la Heráldica, el de la Milicia y el de la Náutica ${ }^{66}$. Sin embargo, en la época en la que Íñigo López de Mendoza escribió su Comedieta ${ }^{67}$, la palabra cuartel en su acepción 'parte de un escudo' constituía un significado inédito en el castellano del siglo $\mathrm{XV}^{68}$. Tanto la documentación histórica manejada como la información procedente de la lexicografía histórica corroboran tal aseveración ${ }^{69}$, por lo que su presencia en la Comedieta de Ponça debió de tener un efecto sorpresivo y novedoso para los hablantes contemporáneos de este decir narrativo. Seguramente, el hecho de que Îñigo López de Mendoza la utilice en el marco de esta ficción alegórica responde al potencial evocador de sus matices significativos, relacionados con su origen etimológico y con su adscripción temática. En cuanto a su origen etimológico, de acuerdo con el diccionario académico, la voz cuartel se corresponde con la voz francesa quartier. Sin embargo, Corominas-Pascual (1980-1991, II: 260) proponen como étimo de enlace la voz del catalán medieval quarter con el significado de 'parte de un escudo' (Corominas, 2011 [1961]: 160), que constituye, precisamente, el significado que se documenta en la obra literaria de don Íñigo López de Mendoza ${ }^{70}$.

En el ámbito de la lengua catalana medieval, la voz quarter se documenta tempranamente y desarrolla múltiples significados asociados, basados en la organización

65 A la luz de los datos recogidos en el Fichero General de la Real Academia Española, existe otra variante, en quarteles, basada en un trueque de preposición y documentada también durante la primera mitad del siglo XV, como se atestigua en el siguiente ejemplo, documentado en la obra Espejo de verdadera nobleza, de Diego de Valera, 1441: "Ay otras guisas asymesmo en que el escudo puede ser partido, asy commo en quarteles". También en otra obra de Diego de Valera, Tratado de las armas, fechada entre 1458-1471, se documenta esta variante: "El delfín trae las armas de Francia é del delfinado en quarteles". Finalmente, en otra obra del mismo Valera, Tratado de las epístolas, fechada en torno a 1475, vuelve a documentarse: "Paresce que el rey de Francia que oy reyna, que syendo bivo su padre traya las armas de Francia é del delfinado en quarteles".

66 s.v. cuartel, en la edición electrónica del Diccionario de la lengua española de la RAE y ASALE.

67 Según Lapesa (1997: 55-63), la fecha de composición de la Comedieta ha de situarse en el año 1435: "Me parece muy justificada la hipótesis de que la Comedieta estuviese acabada antes de terminar el año 1435; pero no creo necesario suponer que empezara a componerse cuando ya se sabía la liberación de los monarcas prisioneros, esto es, a partir de octubre o noviembre".

68 De acuerdo con la información del Corpus diacrónico del español, esta voz sí que había desarrollado otras acepciones a lo largo de la Edad Media, como la de 'buen trato que los vencedores ofrecen a los vencidos cuando estos se rinden': "Et despues que el dicho ginete fino como quier que uos auiedes ganado a Elche atreuiendome en la uuestra merced di el dicho heredamiento a Gonçalo Martines mio chançeller. Agora este Gonçalo Martines dixo me que don Ferrer es quartel que es por uos bayle en la uuestra tierra del regno de Murçia quel quiere tomar este heredamiento" (1305, anónimo, documento notarial) y 'pared del navío situada en su parte delantera': "La tormenta hera cada vez más fuerte. Los marineros alçaron un poco las velas, entraron las pujas e fizieron braguerotes a la vela; e entraron la osta e la sosta; e pusieron dos honbres a las vetas a guindar, e fizieron cataldo para amaynar la fuerça del viento. Hera el viento al quartel de proa" (1431-1449, Gutierre Díaz de Games, El Victorial).

69 Para un estudio detallado de su formación y evolución, véase Vicente Llavata (2013: 419-424).

70 Riquer (1986: 225) señala que el término general en el castellano del XIV es cuarterón, documentado en el Libro de las armas de don Juan Manuel y en el Libro del conosçimiento. En cambio, en la Cadira de Honor de Juan Rodríguez del Padrón se hace referencia ya a "un escudo quartelado de oro y de sinoble", y en los tratados nobiliarios posteriores ya se registra la unidad fraseológica en quarteles, tal como se ha descrito anteriormente. Especialmente sugestivo es este último dato contextual de la Cadira de Honor, pues esta obra era una de las muchas que nutrían la biblioteca de Íñigo López de Mendoza. 
espacial como el principal procedimiento semántico ${ }^{71}$. El testimonio lexicográfico del Diccionari català-valencià-balear $(D C V B)$ nos ofrece hasta trece acepciones en las que la unidad léxica quarter se codifica a partir del sema 'parte constitutiva (de un todo)' ${ }^{72}$. Así, la acepción segunda 'cadascuna de les quatre parts en què es divideix un escut d'armes partit per una creu' permite comprobar que tal voz tenía amplia presencia en catalán medieval y, especialmente, en los tratados de heráldica catalana (Martí de Riquer, 1983: 59-67 y 300-301) ${ }^{73}$.

El hecho de que Íñigo López de Mendoza se hubiese formado en la polifacética corte de la Corona de Aragón como copero mayor constituye un dato biográfico de gran relevancia para el caso que nos ocupa. Es muy probable, pues, que Íñigo López de Mendoza recordase el empleo de esta $\mathrm{voz}^{74}$ en las numerosas campañas militares en las que sirvió y que fuese, por tanto, uno de los primeros en aclimatarla al discurso literario y extenderse, muy probablemente, desde este ámbito a un uso general.

\subsubsection{La locución a desora}

En la última estrofa de la Comedieta, el poeta finaliza su obra con una pregunta: “¿quién dubdaría / si fui desplaziente o muy consolado, / visto tal caso e tan desastrado, / después convertido en tanta alegría?". Antes, sin embargo, cuenta que, en el momento en el que empieza a despuntar el alba, "la magna prinçesa e su conpañía" desaparecen inesperadamente, como por arte de magia:

Con cándidos rayos forçava el aurora

la espessa tiniebla, e la compelía

a dexar la España, assí que a desora

la magna prinçesa e su conpañía

me fueron absentes, pues ¿quién dubdaría

si fui desplaziente o muy consolado,

visto tal caso e tan desastrado,

después convertido en tanta alegría ${ }^{75}$

Íñigo López de Mendoza expresa la desaparición de las señoras por medio de la locución adverbial a desora ${ }^{76}$. Con ello quiso poner el énfasis en que las damas des-

71 Por ejemplo, en una de esas acepciones 'cadascun dels quatre barris o districtes en què es dividia una ciutat', se puede observar esta configuración semántica, formulada en torno a la organización espacial.

72 Consúltese la edición del Diccionari català-valencià-balear, disponible en http://dcvb.iecat.net/

73 La voz quarter se documenta en dos ocasiones en la Vesió de Bernat de So, poema compuesto por 1330 hexasílabos pareados, escrito entre 1381 y 1382 en una modalidad catalano-occitana, característica de la poesía catalana medieval del siglo XIV y parte del XV. Sin embargo, no se documenta la locución propiamente dicha. A este respecto, Riquer compara el uso de esta voz con la presencia de las voces quartó y quartonat en el incunable de 1483 Lo primer del Chrestià de Francesc Eiximenis. Con todo, hay que tener presente que las obras que se imprimen a finales del siglo XV y durante el siglo XVI — como el caso de Lo primer del Chrestià — se actualizan desde el punto de vista lingüístico para acercarlas a las nuevas comunidades lectoras, por lo que habría que interpretar con cautela estas soluciones léxicas.

74 Y, probablemente, el elemento sorpresivo no solo se circunscribiría a la voz en sí, sino al conjunto de la estructura gramatical, pues parece que tanto en catalán como en occitano y francés se estabilizó con la preposición $a$, mientras que en castellano lo hizo con la preposición en.

75 Pérez Priego (1983-1991: 98), estrofa CXX, vv. 953-960.

76 El diccionario académico codifica dos acepciones complementarias desde el punto de vista semántico: 'fuera 
aparecen de manera repentina, que constituye el significado más frecuente de la locución a desora a lo largo de la Edad Media ${ }^{77}$. De entrada podríamos considerar que se trata simplemente de una unidad fraseológica, cuya única contribución semántica se limita a especificar el modo como se realiza la acción. Sin embargo, si tenemos presente los entornos discursivos en los que se documenta la locución a desora a lo largo de la Edad Media, observaremos que su presencia suele estar acompañada en multitud de casos del verbo maravillar(se):

E acatada la forma de la letra e la manera del escrevir, dixieron al emperador que era Juan Damasceno el qual luego fue traído con gran injuria ante la presencia del emperador. E el maravillándosse onde tan a deshora veniera tan gran alboraço contra él e tan gran malaventura, e todo el pueblo le dezía muchas injurias e denuestos e dezían que non era saçerdote mas traidor e que non era monje mas renegado apostata.

E estando en juizio ante Dios, él mando que tornasse el ánima al cuerpo e faziesse penitencia de sus pecados. E en tanto los monjes, veyendo que tardava el sacristán de tañer a matines, fueronle a buscar e allegaron al río e falláronlo afogado. E sacado el cuerpo del agua, maravillándosse mucho de aquella muerte, a deshora torno el anima al cuerpo e rreconto todo lo que le acaeciera, e despues acabo su vida en buenas obras.

Tal como podemos observar en los contextos aducidos pertenecientes al Libro de los exemplos por A.B.C $C^{78}$, la combinación del verbo maravillarse junto con la locución a deshora presenta como función textual conferir un carácter sorpresivo y sobrenatural a lo que se narra. En el primer contexto, el monarca se sorprende en gran manera de la reacción intempestiva y furiosa del pueblo hacia Juan Damasceno; el carácter sorpresivo o de ruptura con lo esperado viene determinado por la contradicción entre los valores que representa Juan Damasceno y la reacción airada del pueblo. En el segundo contexto, el carácter maravilloso viene determinado por el hecho de que resucite el monje y cuente todo lo que le pasó.

Desde el punto de vista de la descripción gramatical, en ambos contextos antecede a la oración principal una construcción de gerundio que funciona como un complemento oracional. Por su parte, la locución a desora se sitúa en el entorno próximo del verbo principal, al cual modifica desde el punto de vista semántico.

Por otra parte, resulta altamente significativo para nuestro propósito que el verbo maravillar y su respectiva familia léxica (maravilla, maravillado, a maravilla) se documenten muy profusamente en el subgénero literario conocido como "relato

de sazón o de tiempo' y 'de repente, intempestivamente'. Dicho sea de paso, existe, a nuestro entender, un principio de contradicción en la definición de ambas acepciones, pues, si buscamos en el diccionario el adjetivo intempestivo, su significado 'que es o está fuera de tiempo y sazón' nos indica que la primera acepción podría ir acompañada del adverbio intempestivamente, mientras que en la segunda acepción se podría añadir el adverbio súbitamente para completar el significado de la locución adverbial de repente. Dispuesta la información de este modo, creemos que se evitaría esa contradicción aludida.

77 En un estudio todavía inédito que estamos emprendiendo, se observa que el significado general de esta unidad hasta la primera mitad del siglo XV es el de 'repentinamente'.

78 Se ha seguido la edición crítica elaborada por Gutiérrez Martínez (2011). 
de viajes"79. De hecho, la familia léxica de maravillar puede considerarse como un claro nexo articulador de este subgénero, por cuanto constituye el reflejo formal de la materia descriptiva que recogen los libros de viajes y da cuenta, además, de la relación permeable entre lo real y lo maravilloso ${ }^{80}$, tal como se muestra en este fragmento de la Embajada a Tamorlán ${ }^{81}$ :

En esta plaça, ante la iglesia, estava una colupna de piedra, muy alta a maravilla; $\mathrm{e}$ encima d'ella estava una grand losa llana; e encima d'ella estava puesto un cavallo de cobre, atan grande como podrían ser cuatro cavallos grandes [...].

En el caso que nos ocupa, pese a que no aparece de manera explícita ninguna referencia al hecho maravilloso de que las damas desaparezcan sin dejar rastro ${ }^{82}$, la presencia de la locución a desora constituye, a nuestro modo de ver, un índice relevante de representar lo ficticio, percibido por el matiz semántico 'de forma repentina', 'como por arte de magia' ${ }^{83}$. Todo ello nos hace considerar la idoneidad que presentan estos conocimientos en relación con las tareas propias de la Crítica Textual, en el sentido de que permiten anotar el texto de una manera más completa $y$, a su vez, iluminar ciertos pasajes en la compleja tarea de interpretación de la obra literaria.

\section{Consideraciones finales}

En un intento por envolver emocionalmente al público de la época en un ambiente de misterio e irrealidad, Íñigo López de Mendoza recurre a numerosos recursos expresivos con el fin de recrear el carácter ficticio de lo que se poetiza. De entre todos ellos, hemos destacado tres modos de "recontar" la ficción alegórica: el uso de latinismos léxicos, la presencia de voces prestadas y el uso de locuciones formadas con palabras diacríticas. Nos interesa destacar especialmente el uso de estas últimas, por cuanto han pasado más desapercibidas para la crítica literaria y son objeto, además, de renovado interés filológico ${ }^{84}$.

En el caso de los latinismos léxicos y en el de las voces prestadas, una de las condiciones ineludibles para considerar a estos elementos léxicos como recursos potenciadores de la ficción alegórica se basa en la necesidad de que deben ser primeras documentaciones en este segmento temporal, pues este hecho de tipo cronológico

79 Para un estudio de conjunto sobre la literatura de viajes desde el punto de vista histórico-literario, consúltense los trabajos de Pérez Priego (1984), Rubio Tovar (1986), Beltrán Llavador (1991), Carrizo Rueda (1994) y López Estrada (2003).

80 Para un estudio de las unidades fraseológicas presentes en los libros de viajes castellanos medievales del siglo XV, véase el estudio de Vicente Llavata (2006).

81 Seguimos la edición crítica preparada por López Estrada (1999).

82 Nos referimos a la presencia de alguna palabra relacionada con la familia léxica de la voz maravilla.

83 Otro dato contextual en la misma Comedieta (estrofa I, vv. 1-8) también parece apuntar al mismo matiz semántico: “ ¡O vos, dubitantes, creed las istorias / e los infortunios de los humanales, / e ved si los triumphos, honores e glorias / e grandes poderes son perpetuales! / Mirad los imperios e casas reales, / e cómo Fortuna es superiora: / rebuelve lo alto en baxo a desora / e faze a los ricos e pobres iguales".

84 Véase, a este respecto, la nota con que se inicia este artículo, así como la nota a pie de página 55, en la que se hace referencia a la bibliografía fundamental sobre fraseología histórica. 
justificaría el efecto sorpresivo ${ }^{85}$ que se deduciría de su recepción en el castellano del siglo XV.

En cuanto al uso de fraseología, el análisis estilístico efectuado nos muestra que las locuciones formadas con palabras diacríticas se conforman como un potente recurso orientado a potenciar el carácter ficticio de lo narrado, precisamente por la presencia de una voz inédita y no disponible en el vocabulario general a ojos (y oídos) del público de estas obras.

\section{Obras citadas}

Alcover Sureda, Antoni $\mathrm{M}^{\mathrm{a}}$; Moll i Marquès, Aina $\mathrm{M}^{\mathrm{a}}$; Moll Casanova, Francesc de Borja y Sanchis Guarner, Manuel: Diccionari català-valencià-balear (10 vols.), Palma, Editorial Moll, 1962-1993.

Alvar, Carlos: "Boccaccio en Castilla: entre recepción y traducción", en La Recepción de Boccaccio en España. Actas del Seminario Internacional Complutense (18-20 de octubre de 2000), Cuadernos de Filología Italiana, ed. María Hernández Esteban, 2001, pp. 333350.

Álvarez Vives, Vicente: Estudio fraseológico contrastivo de los diccionarios de Vicente Salvá y de Esteban Pichardo. Hacia una fraseografia histórica del español en la lexicografía del siglo XIX, Valencia, Universitat de València (Anejo 79 de Quaderns de Filologia), 2013.

Arce, Joaquín: Boccaccio humanista y su penetración en España, Madrid, Fundación Universitaria Española, 1975.

Arce, Joaquín: "Boccaccio nella letteratura castigliana", en Il Boccaccio nelle culture e letterature nazionali, ed. F. Mazzoni, Florencia, Olschki, 1978, pp. 63-109.

Beltrán Llavador, Rafael: "Los libros de viajes castellanos. Introducción al panorama crítico actual", Revista de Filología Románica, I (1991), pp. 121-164.

Beltrán Llavador, Rafael (coord.): Maravillas, peregrinaciones y utopias; literatura de viajes en el mundo románico, Valencia, Universitat de València, 2002.

Beltrán Pepió, Vicenç: La canción de amor en el otoño de la Edad Media, Barcelona, PPU, 1988.

Beltrán Pepió, Vicenç: "La encrucijada de Santillana", en Íñigo López de Mendoza, marqués de Santillana, Comedieta de Ponza, sonetos, serranillas y otras obras, ed. de Régula Rohldan de Langbehn, Barcelona, Crítica, 1997, pp. ix-xxx.

Beltrán Pepió, Vicenç: Edad Media: lírica y cancioneros, Madrid, Visor, 2009.

Cabré, Lluís: "Notas sobre la memoria de Santillana y los poetas de la Corona de Aragón", en Cancionero Studies in Honour of Ian Macpherson, ed. A. Deyermond, London, Department of Hispanic Studies - Queen Mary and Westfield College, 1998, pp. 25-38.

Caravaggi, Giovanni: "Petrarch in Castile in the Fifteenth Century: The Triunfete de Amor by the Marquis de Santillana», en Petrach's «Triumphs", en Allegory and Spectacle, eds. Konrad Eisenbichler y Amilcare A. Iannuci, Toronto, University of Toronto, 1990, pp. 291-306.

Carrizo Rueda, Sofía: "Hacia una poética de los relatos de viajes. A propósito de Pero Tafur", Incipit, XIV (1994), pp. 103-144.

\footnotetext{
5 Recuérdese el significado de alegoría como 'habla extraña, ininteligible'.
} 
Casares Sánchez, Julio: Introducción a la lexicografía moderna, Madrid, CSIC, 1992.

Cátedra, Pedro M.: "El sentido involucrado y la poesía de siglo XV. Lecturas virgilianas de Santillana, con Villena", en Nunca fue pena mayor. Estudios de literatura española en homenaje a Brian Dutton, eds. Ana Menéndez Collera y Victoriano Roncero López, Cuenca, Ediciones de la Universidad de Castilla-La Mancha, 1996, pp. 149-162.

Clavería Nadal, Gloria: El latinismo español, Barcelona, Bellaterra, 1991.

Colón Domènech, Germà: "Rocinante no es pariente de rozagante", en Para la historia del léxico español, eds. Albert Soler y Núria Mañé, Madrid, Arco/Libros, 2002, pp. 373-402.

Corominas Vigneaux, Joan y Pascual Rodríguez, José Antonio: Diccionario crítico etimológico castellano e hispánico (6 vols.), Madrid, Gredos, 1980-1991.

Corominas Vigneaux, Joan: Breve diccionario etimológico de la lengua castellana, Madrid, Gredos, [1961], 2011.

Corpas Pastor, Gloria: Manual de fraseología española, Madrid, Gredos, 1996.

de Bustos Tovar, José Jesús: Contribución al estudio del cultismo léxico medieval, Madrid, Real Academia Española, 1974.

Deyermond, Alan: "Las sirenas, el unicornio y el áspid: sonetos 21, 23 y 26 de Santillana", en Alan Deyermond, Poesía de cancionero del siglo XV. Estudios seleccionados, ed. R. Beltrán, J. L. Canet y M. Haro, València, Universitat, (Col·lecció Honoris Causa 24), 2007, pp. 175-203.

Dworkin, Steven N.: "La transición léxica en el español bajomedieval", en Historia de la lengua española, coord. Rafael Cano Aguilar, Barcelona, Ariel, 2005², pp. 643-656.

Eberenz, Rolf: "La catalanitat “subjacent” de l'Arte Cisoria d'Enric de Villena", en Estudis de llengua i literatura catalanes. Miscel·lània Germà Colon (vol. 4), Barcelona, Publicacions de l'Abadia de Montserrat, 1995, pp. 95-106.

Echenique Elizondo, María Teresa: "Pautas para el estudio histórico de las unidades fraseológicas", en Homenaje a José Jesús de Bustos Tovar, eds. José Luis Girón, Ramón Santiago y Eugenio de Bustos, Madrid, Editorial Complutense, 2003, pp. 545-560.

Echenique Elizondo, María Teresa: "Notas de sintaxis histórica en el marco del corpus de diacronía fraseológica del español (DIAFRAES)", en Romanische Syntax in Wandel, eds. Elisabeth Stark, Roland Schmidt-Riese y Eva Stoll, Tübingen, Gunter Narr Verlag, 2008a, pp. 387-392.

Echenique Elizondo, María Teresa: “Algunas notas sobre latín y romance en la fraseología hispánica medieval", en Latin vulgaire - latin tardif VIII: Actes du VIII colloque international sur le latin vulgaire et tardif (Oxford, 6-9 de septiembre de 2006), ed. Roger Wright, Oxford, St. Catherine's College, 2008b, pp. 540-547.

Echenique Elizondo, María Teresa y Martínez Alcalde, María José: Diacronía y gramática histórica de la lengua española, Valencia, Tirant Humanidades (Edición revisada y actualizada), $2013^{2}$.

Enrique-Arias, Andrés (dir.) y Pueyo Mena, Francisco Javier (dir. técnico): Biblia Medieval. En línea <http:/www.bibliamedieval.es>, 2008, [12/01/2015].

García-Page Sánchez, Mario: "Locuciones adverbiales con palabras idiomáticas”, Revista Española de Lingüística, 21, 2 (1991), pp. 231-264.

García-Page Sánchez, Mario: Introducción a la fraseología española. Estudio de las locuciones, Barcelona, Anthropos, 2008.

García Valle, Adela: "El reflejo de los arcaísmos lingüísticos en el Fuero general de Navarra (siglo XV)", Analecta Malacitana, XXX, 1 (2007), pp. 151-159.

Gómez Moreno, Ángel: España y la italia de los humanistas: primeros ecos, Madrid, Gredos, 1994. 
Gómez Moreno, Ángel: “Del Duecentro al Quattrocento: Italia en España, España en Italia”, Ínsula. Revista de letras y ciencias humanas, 757-758, (2010), pp. 7-11.

Gómez Moreno, Ángel y Kerkhof, Maxim. P. A. M. (eds.): Poesías completas (Marqués de Santillana), Madrid, Clásicos Castalia, 2003.

Gómez Redondo, Fernando: Historia de la prosa medieval castellana, II. El desarrollo de los géneros. La ficción caballeresca y el orden religiosos, Madrid, Cátedra, 1999.

Gómez Redondo, Fernando: Historia de la prosa medieval castellana, III. Los orígenes del humanismo. El marco cultural de Enrique III y Juan II, Madrid, Cátedra, 2002.

Gutiérrez Carou, Javier: La influencia de la Divina Commedia en la poesía castellana del siglo XV, Santiago de Compostela, Universidade, 1996.

Gutiérrez Carou, Javier: "La visión alegórica de tres damas en la obra de Dante, Villasandino y el Marqués de Santillana", en AHLM. Actas VI Congreso; ed. J. M. Lucía, Alcalá, Universidad, I, 1997, pp. 737-747.

Gutiérrez Martínez, $\mathrm{M}^{\mathrm{a}}$ del Mar (ed.): Libro de los exemplos por A.B.C, Memorabilia. Boletín de Literatura Sapiencial, 12, 13 y 15 (2009-2013), pp. 1-629.

Institut d'Estudis Catalans: Diccionari de la llengua catalana, Barcelona, Edicions 62, Enciclopèdia Catalana, 2007.

Instituto de Investigación Rafael Lapesa de la Real Academia Española (2013- ): Nuevo diccionario histórico de la lengua española (NDHE) [en línea]. $<$ http://web.frl.es/DH> [Consulta: 10/01/2015]

Kabatek, Johannes y Jacob, Daniel (ed.): Lengua medieval y tradiciones dircursivas en la Península Ibérica. Descripción gramatical. Pragmática histórica y metodología. Frankfurt, Madrid, Vervuert, Lingüística Iberoamericana, 2001.

Kabatek, Johannes (ed.): Sintaxis histórica del español y cambio lingüistico: nuevas perspectivas desde las Tradiciones Discursivas, Frankfurt, Madrid, Vervuert, Lingüística Iberoamericana, 2008.

Lapesa Melgar, Rafael: Los decires narrativos del Marqués de Santillana. Discurso leído el 21 de Marzo de 1954 en su recepción pública por Rafael Lapesa Melgar y contestación de Dámaso Alonso, Madrid, Real Academia Española, 1954.

Lapesa Melgar, Rafael: La obra literaria del Marqués de Santillana, Madrid, Ínsula, 1957.

Lapesa Melgar, Rafael: Historia de la lengua española, Madrid, Gredos, $1981^{9}$.

Lida de Malkiel, María Rosa: Estudios sobre la literatura española del siglo XV, Madrid, José Porrúa Turanzas, 1978.

Lida de Malkiel, María Rosa: Juan de Mena: poeta del prerrenacimiento español, México, El Colegio de México, 1984² (adicionada por Yakov Malkiel).

Lida de Malkiel, María Rosa: La idea de la fama en la Edad Media castellana, México, Fondo de Cultura Económico, 2006.

Lleal Galceran, Coloma (dir.): DiCCA-XV. El castellano del siglo XV en la Corona de Aragón, Grup d'Història i Contacte de Llengües (GHCL) [en línea]: $<$ http://stel.ub.edu/diccaxv/home/index/myLanguage:es $>$, Barcelona, Universidad de Barcelona [Fecha de la consulta: 12 de enero de 2015].

López Estrada, Francisco (ed.): Embajada a Tamorlán, Madrid, Castalia, 1999.

López Estrada, Francisco: Libros de viajeros hispánicos medievales, Madrid, Ediciones del Laberinto, 2003.

López Bascuñana, Isabel: “Cultismos, arcaísmos, elementos populares y lenguaje paremiológico en la obra del Marqués de Santillana”, Anuario de Filología, 3 (1977), pp. 279-313. Martínez Marín, Juan: Estudios de fraseología española, Málaga, Ágora, 1996.

Montoro del Arco, Esteban Tomás: Teoría fraseológica de las locuciones particulares. Las 
locuciones prepositivas, conjuntivas y marcadoras en español, Frankfurt am Main, Peter Lang, 2006.

Pascual Rodríguez, José Antonio: La traducción de la Divina commedia atribuida a D. Enrique de Aragón: estudio y edición del infierno, Salamanca, Universidad de Salamanca (Col. Acta Salmanticensia, 82), 1974.

Penadés Martínez, Inmaculada: Gramática y semántica de las locuciones, Alcalá de Henares, Publicaciones de la Universidad de Alcalá de Henares (Col. Monografías Humanidades, 42), 2012.

Pérez Priego, Miguel Ángel: "Estudio literario de los libros de viajes medievales", Épos, I (1984), pp. 217-239.

Pérez Priego, Miguel Ángel (ed.): Poesías completas (Marqués de Santillana), Madrid, Alhambra, 1983-1991.

Pérez Priego, Miguel Ángel: “Apuntes sobre la presencia de la literatura medieval en la poesía contemporánea", Medievalismo. Boletín de la Sociedad Española de Estudios Medievales, 10 (2000), pp. 361-384.

Pérez Priego, Miguel Ángel: "Marqués de Santillana", en Diccionario filológico de literatura medieval española. Textos y transmisión, coords. Carlos Alvar y José Manuel Lucía, Madrid, Castalia, 2002, pp. 843-853.

Pérez Priego, Miguel Ángel: "El Marqués de Santillana y la Corona de Aragón en el marco del Humanismo peninsular", Revista de lenguas y literaturas catalana, gallega y vasca, IX (2003), pp. 29-36.

Pérez Priego, Miguel Ángel: Estudios sobre la poesía del siglo XV, Madrid, Universidad Nacional de Educación a Distancia, 2004.

Pérez Priego, Miguel Ángel: Boccaccio en la obra literaria de Santillana, Alicante, Biblioteca Virtual Miguel de Cervantes, 2011.

Pla Colomer, Francisco Pedro: Métrica, rima y oralidad en el Libro de buen amor, Valencia, Universitat de València (Anejo 80 de Quaderns de Filologia), 2012.

Pla Colomer, Francisco Pedro: Letra y voz de los poetas en la Edad Media Castellana, Valencia, Tirant Humanidades (Col. Diachronica Hispanica, 3), 2014.

Real Academia Española. Banco de datos (CORDE) [en línea], Corpus diacrónico del español, <http://www.rae.es> [20/06/2009].

Real Academia Española. Fichero General de la Real Academia Española [en línea], <http:// web.frl.es/fichero.html> [7/01/2015].

Real Academia Española y Asociación de Academias de la lengua española: Diccionario de la lengua española, Madrid, Espasa-Calpe, 2014.

Rico, Francisco: Historia y crítica de la literatura española, vol. I (al cuidado de Alan Deyermond), Barcelona, Crítica, 1980.

Rico, Francisco: Texto y contextos. Estudios sobre la poesía española del siglo XV, Barcelona, Crítica, 1990.

Rico, Francisco: El sueño del Humanismo. De Petrarca a Erasmo, Barcelona, Destino, 2002.

Riquer, Martí de: Heràldica catalana des de l'any 1150 al 1550, Barcelona, Quaderns Crema, 1983.

Riquer, Martí de: Heráldica castellana en tiempos de los Reyes Católicos, Barcelona, Quaderns Crema, 1986.

Rohldan de Langbehn, Regula (ed.): Comedieta de Ponza, sonetos, serranillas y otras obras, ed. de, Barcelona, Crítica, 1997.

Rubio Tovar, Joaquín: Libros españoles de viajes medievales, Madrid, Taurus, 1986. 
Ruiz Gurillo, Leonor: Aspectos de fraseología teórica española, Valencia, Universitat de València, 1997.

Ruiz Gurillo, Leonor: Las locuciones en el español actual, Madrid, Arco/Libros (Cuadernos de lengua española, 71), 2001.

Schiff, Mario: La bibliothèque du Marquis de Santillane, Paris, 1905 (reimp. G. Olms, Hildesheim-Nueva York, 1978).

Taylor, Barry: "Santillana and Allegory", en Santillana: A Symposium, ed. A. Deyermond, London, Department of Hispanic Studies, Queen Mary and Westfield College, 2000, pp. 39-51.

Vicente Llavata, Santiago: "La fraseología en los libros de viajes castellanos del siglo XV", en Actas del VI Congreso Internacional de Historia de la Lengua Española (Madrid, 29 de septiembre al 3 de octubre de 2003), eds. José Jesus de Bustos Tovar y José Luis Girón Alconchel, Madrid, Universidad Complutense-Arco/Libros, Asociación de Historia de la Lengua Española, 2006, pp. 2091-2101.

Vicente Llavata, Santiago: "La locución a temps / a tiempo en el marco del Humanismo peninsular", Paremia, 17, 2008, pp. 121-130.

Vicente Llavata, Santiago: Estudio de las locuciones en la obra literaria de don Íñigo López de Mendoza. Hacia una Fraseología histórica del español, Valencia, Universitat de València (Anejo 76 de Quaderns de Filologia), 2011.

Vicente Llavata, Santiago: "Íñigo López de Mendoza y su secreta labor de codificación fraseológica”, en A. García Valle, A. Ricós y J. P. Sánchez Méndez (eds. y coords.), Fablar bien e tan mesurado. Veinticinco años de investigación diacrónica en Valencia. Estudios ofrecidos a $M^{a}$ Teresa Echenique Elizondo en conmemoración de su Cátedra, Valencia, Tirant Humanidades / Université de Neuchâtel [Col. Diachronica Hispanica 2], pp. 87110 .

Vicente Llavata, Santiago: "Notas de fraseología hispánica medieval. A propósito de la impronta catalano-aragonesa en la obra literaria de don Íñigo López de Mendoza", en Actas del XXVI Congreso Internacional de Lingüística y Filología Románicas (Valencia, del 6 al 11 de septiembre de 2010), eds. Cesáreo Calvo y Emili Casanova, Berlín, DeGruyter, 2013, pp. 417-427.

Vicente Llavata, Santiago: "Fraseología hispánica medieval y codificación. A propósito de la traducción aragonesa del Secretum secretorum promovida por Juan Fernández de Heredia”, en Fraseología española: diacronía y codificación, ed. de Mª T. Echenique Elizondo, Ma . J. Martínez Alcalde, Juan P. Sánchez Méndez y Francisco P. Pla Colomer, Madrid, Consejo Superior de Investigaciones Científicas (Anejos de la Revista de Filología Española, 104), 2016, pp. 75-96.

Wotjak, Gerd (ed.): Estudio de fraseología y fraseografía del español actual, Madrid, Frankfurt am Main, Lingüística iberoamericana, Vervuert (Col. Lingüística iberoamericana, 6), 1998.

Zuluaga Ospina, Alberto: Introducción al estudio de las expresiones fijas, Tübingen, Max Hueber Verlag, 1980. 